\title{
Removal of oxidative stress and genotoxic activities during drinking water production by ozonation and granular activated carbon filtration
}

\author{
Maria Yu ${ }^{1 *} \mathbb{0}$, Elin Lavonen ${ }^{2,3}$, Agneta Oskarsson $^{1}$ and Johan Lundqvist ${ }^{1}$
}

\begin{abstract}
Background: Bioanalytical tools have been shown to be useful in drinking water quality assessments. Here, we applied a panel of in vitro bioassays to assess the treatment efficiency of two pilot-scale treatments: ozonation and granular activated carbon (GAC) filtration at a drinking water treatment plant (DWTP). The pilot-scale systems were studied alongside a full-scale treatment process consisting of biological activated carbon (BAC) filtration, UV disinfection, and monochloramine dosing. Both systems were fed the same raw water treated with coagulation/flocculation/ sedimentation and sand filtration. The endpoints studied were oxidative stress (Nrf2 activity), genotoxicity (micronuclei formations), aryl hydrocarbon receptor (AhR) activation, as well as estrogen receptor (ER) and androgen receptor (AR) activity.

Results: Nrf2, AhR, and ER activities and genotoxic effects were detected in the incoming raw water and variability was observed between the sampling events. Compared to most of the samples taken from the full-scale treatment system, lower Nrf2, AhR, and ER bioactivities as well as genotoxicity were observed in all samples from the pilot-scale systems across all sampling events. The most pronounced treatment effect was a 12-fold reduction in Nrf2 activity and a sixfold decrease in micronuclei formations following ozonation alone. GAC filtration alone resulted in sevenfold and fivefold reductions in Nrf2 activity and genotoxicity, respectively, in the same sampling event. Higher bioactivities were detected in most samples from the full-scale system suggesting a lack of treatment effect. No androgenic nor anti-androgenic activities were observed in any sample across all sampling events.

Conclusions: Using effect-based methods, we have shown the presence of bioactive chemicals in the raw water used for drinking water production, including oxidative stress, AhR and ER activities as well as genotoxicity. The currently used treatment technologies were unable to fully remove the observed bioactivities. Ozonation and GAC filtration showed a high treatment efficiency and were able to consistently remove the bioactivities observed in the incoming water. This is important knowledge for the optimization of existing drinking water treatment designs and the utilization of alternative treatment technologies.
\end{abstract}

Keywords: Drinking water, In vitro bioassays, Toxicity, Treatment efficacy, Repeat sampling, Pilot-scale

*Correspondence: maria.yu@slu.se

${ }^{1}$ Department of Biomedical Sciences and Veterinary Public Health, Swedish University of Agricultural Sciences, Box 7028, 75007 Uppsala, Sweden

Full list of author information is available at the end of the article

\section{Introduction}

Drinking water sources, particularly surface water, are increasingly subject to contamination risks from various anthropogenic activities including agricultural land use, urban stormwater discharge, wastewater treatment plant
SpringerOpen

(c) The Author(s) 2021. Open Access This article is licensed under a Creative Commons Attribution 4.0 International License, which permits use, sharing, adaptation, distribution and reproduction in any medium or format, as long as you give appropriate credit to the original author(s) and the source, provide a link to the Creative Commons licence, and indicate if changes were made. The images or other third party material in this article are included in the article's Creative Commons licence, unless indicated otherwise in a credit line to the material. If material is not included in the article's Creative Commons licence and your intended use is not permitted by statutory regulation or exceeds the permitted use, you will need to obtain permission directly from the copyright holder. To view a copy of this licence, visit http://creativecommons.org/licenses/by/4.0/. 
outlets and long-distance air pollution. As a result, there is growing concern over the presence of micropollutants in water sources and their potential negative effects on the environment and in drinking water production. Further, the presence of naturally occurring toxicants in raw water, as well as the formation of disinfection byproducts (DBPs) during drinking water production, pose potential threats to human health [1-3]. Such challenges facing the drinking water sector, thus, call for continued research to not only better understand and predict the removal rates of treatment technologies and support the optimization of water purification strategies, but also to inform more comprehensive water quality frameworks to ultimately safeguard the hygienic quality of drinking water.

Effective water treatment processes are essential to produce safe drinking water under varying source-water quality conditions. Drinking water purification methods commonly utilized at drinking water treatment plants (DWTPs) include different combinations of the following basic physical and chemical processes: coagulation, sedimentation, filtration, and disinfection [chlorination or ultraviolet (UV) irradiation]. These methods, however, do not completely eliminate micropollutants that may remain in the treated drinking water [4] and lead to human exposure to hazardous compounds or mixtures. As such, the choice and combination of treatment methods are important considerations in the design of DWTPs. Chlorination remains a common disinfection method at DWTPs around the world. In the US alone, disinfection using free chlorine continues to be the most widely used disinfectant, as reported by $70 \%$ of respondents in a recent survey summarizing common disinfection practices among drinking water utilities [5]. Cost has been reported as the primary factor as to why the utility operators have not considered switching to other disinfection methods such as ozone or UV [5]. Similarly, chlorination is widely used in other countries such as South Africa, Canada, and Australia [6]. However, a major downside of using chlorine is the potential formation of DBPs such as trihalomethanes (THMs) and haloacetic acids (HAAs). Alternative disinfectants such as chloramines, ozone, chlorine dioxide, and UV disinfection are, however, gaining popularity. Ozonation $\left(\mathrm{O}_{3}\right)$ and activated carbon treatments have been suggested to be more effective treatment methods in managing the removal of organic micropollutants (OMPs) and DBP precursors [7, 8] than other methods such as coagulation, sedimentation, and rapid or slow sand filtration. Certainly, water treatment methods continue to be modernized with the development of advanced treatment alternatives. While each treatment method has its advantages and disadvantages, it is undoubtedly beneficial to pilot-test treatment designs prior to implementation to ensure the designs are appropriately suited for implementation into full-scale capacities or when considering the optimization of existing treatment system processes.

The efficiencies of treatment processes at a DWTP are routinely tracked via drinking water quality monitoring. However, such monitoring is typically only conducted for the limited number of chemical parameters listed in the drinking water regulations, such as metals, pesticides, a few DBPs, and polycyclic aromatic hydrocarbons. Such parameters alone are insufficient in characterizing water quality given that numerous chemicals are likely to be present and potentially at low concentrations. As such, effect-based monitoring using bioanalytical tools (i.e., in vitro bioassays) has been suggested as a promising complement to existing water quality assessments [9-17] and can provide valuable information related to treatment efficiencies. Importantly, more studies using bioanalytical tools to assess DWTPs are needed to provide support towards the acceptance and implementation of in vitro bioassays in drinking water quality regulations.

In the current study, a panel of cell-based reporter gene assays assessing effects from multiple toxicity pathways relevant to human health were used to investigate the treatment efficiencies of a pilot-scale drinking water system. Specifically, the study compared the efficacy of pilot-scale GAC filtration as well as the combination of ozonation and GAC filtration vs. full-scale biological activated carbon (BAC) filtration, UV disinfection, and monochloramine dosing at removing/reducing bioactivities. Both treatment systems were fed the same raw water that had undergone primary treatment (coagulation, sedimentation/flotation, sand filtration) in the full-scale. We hypothesized that the ozonation and GAC filtration methods would be more effective at reducing bioactivities. The selected bioassays targeted reactive modes of action such as cytotoxicity and genotoxicity as well as adaptive stress responses and receptor-based effects including oxidative stress, aryl hydrocarbon receptor (AhR) activation, and hormone-mediated modes of action. These particular endpoints, which relate to adaptive stress response, xenobiotic metabolism, and modulation of hormone systems, have been identified as being the most responsive toxicity pathways in the case of drinking water $[2,18,19]$. This study aimed to: (1) provide knowledge on the efficacy of the pilot-scale ozonation and GAC filtration treatments; (2) assess temporal differences in water quality; and (3) report findings regarding bioactivities observed in the raw water and the full-scale treatment process. While the efficacy of the pilot-scale ozone $\left(\mathrm{O}_{3}\right)$ and GAC had been previously assessed in the context of OMP levels in drinking water production [8], the bioanalytical approach of the current study will 
provide further useful information regarding the removal efficiencies of the two treatment technologies. This could be of particular relevance as a decision-making tool in the potential implementation of the alternate treatment technologies into full-scale capacities or when considering the optimization of the existing treatment system processes.

\section{Materials and methods}

\section{Conventional full-scale and pilot-scale treatment systems}

Görvälnverket is one of three DWTPs operating in the Stockholm region of Sweden. This facility draws untreated raw water from Lake Mälaren and services almost 700,000 consumers in several regional municipalities. Lake Mälaren is the third largest freshwater lake in Sweden and also receives effluent from several wastewater treatment plants located upstream of the DWTP [20]. Görvälnverket was built in 1929 and the facility has undergone several upgrades over the years. To meet the increasing demand for drinking water from the growing municipalities, additional upgrades are currently being considered for the DWTP.

Raw water entering Görvälnverket undergoes several conventional treatment processes consisting of: micro-sieving followed by coagulation treatment using aluminum sulfate, flocculation and sedimentation/flotation, rapid sand filtration, biologically activated carbon (BAC) filtration, UV disinfection, and lastly dosing with monochloramine $\left(\mathrm{NH}_{2} \mathrm{Cl}\right)$ for secondary disinfection and lime for alkalinization and $\mathrm{pH}$ adjustment (Table 1, Fig. 1). The BAC filters have a running time of approximately $10-15$ years and a short empty bed contact time (EBCT) of approximately 4-6 min.

A pilot-scale water treatment system consisting of ozonation pre-treatment and GAC columns (Table 1, Fig. 1) was installed at Görvälnverket in May 2018 to evaluate the efficacy of these two methods in removing, e.g., OMP and DOC removal. This pilot-scale system receives incoming water treated with coagulation, sedimentation, and sand filtration from the full-scale treatment system at a flow rate of $610-720 \mathrm{~L} / \mathrm{h}$. In this study, two pilot-scale processes were investigated: (1) pilot-scale A wherein the incoming primary-treated water undergoes ozonation then GAC filtration; and (2) pilot-scale B wherein the incoming primary-treated water undergoes GAC filtration without pre-ozonation. For pilot-scale A, feed water was $\mathrm{pH}$-adjusted to 6.5 prior to ozonation (target residual of $1 \mathrm{mg} \mathrm{O} / \mathrm{L}$ after 4.2-4.9 min reaction) while the pilot-scale B GAC column received water at ambient coagulation $\mathrm{pH}$ (6.56.8). The GAC column in pilot-scale B is used to: (a) directly assess differences in GAC efficacy with and without pre-ozonation; and (b) to investigate the gradual saturation of a GAC filter with longer EBCT and compare it to the full-scale short EBCT BAC treatment. The EBCTs for pilot-scale A and B were $20 \mathrm{~min}$.

Table 1 Water sample identifications (IDs) and description of treatment and sampling locations at Görvälnverket DWTP

\begin{tabular}{|c|c|c|}
\hline Sample ID & Sampling point & Treatment/location description \\
\hline \multicolumn{3}{|c|}{ Full-scale treatment process } \\
\hline RW & Incoming raw water & $\begin{array}{l}\text { Incoming raw water to Görvälnverket from lake Mälaren (Görväln basin) at } 4 \mathrm{~m} \\
\text { or } 22 \mathrm{~m} \text { depth, after micro sieve, ambient pH }\end{array}$ \\
\hline SF & After coagulation and sand filtration & $\begin{array}{l}\text { After coagulation/flocculation, sedimentation (or flotation) and sand filtration, } \\
\mathrm{pH} \approx 6.5-6.8\end{array}$ \\
\hline BAC & After BAC filter & $\begin{array}{l}\text { After the oldest full-scale filter (approx. } 13 \text { years, EBCT 5-6 min), Norit }{ }^{\circledR} 830 \text { W, } \\
\mathrm{pH} \approx 6.5-6.8\end{array}$ \\
\hline UV & After UV & After UV disinfection $\left(400 \mathrm{~J} / \mathrm{m}^{2}\right), \mathrm{pH} \approx 6.5-6.8$ \\
\hline DW & After $\mathrm{NH}_{2} \mathrm{Cl}$ - finished drinking water & $\begin{array}{l}\text { After the addition of monochloramine ( } 0.2-0.38 \mathrm{mg} \text { excess chlorine/L) and } \\
\text { lime, } \mathrm{pH} \approx 8-8.3\end{array}$ \\
\hline TAP-1 & Tap water location \# 1 & $\begin{array}{l}\text { From a faucet at a location approximately } 6 \mathrm{~km} \text { in the distribution network } \\
\text { from Görvälnverket }\end{array}$ \\
\hline TAP-2 & Tap water location \#2 & $\begin{array}{l}\text { From a faucet at a location approximately } 50 \mathrm{~km} \text { in the distribution network } \\
\text { from Görvälnverket }\end{array}$ \\
\hline \multicolumn{3}{|c|}{ Pilot-scale treatment process A } \\
\hline $\mathrm{O}_{3}$ & After ozone treatment & $\begin{array}{l}\text { After approximately } 20 \text { min of ozonation of sand filtrate water from full-scale, } \\
\mathrm{pH} \approx 6.5\end{array}$ \\
\hline GAC-A & After GAC-A & $\begin{array}{l}\text { Ozonated sand filtrate feed water, after treatment through a Norit }{ }^{\circledR} 1240 \mathrm{~W} \\
\text { GAC filter column, EBCT } 20 \mathrm{~min}, \mathrm{pH} \approx 6.5\end{array}$ \\
\hline \multicolumn{3}{|c|}{ Pilot-scale treatment process B } \\
\hline GAC-B & After GAC-B & $\begin{array}{l}\text { Sand filtrate feed water, no ozonation, after treatment through a Norit }{ }^{\circledR} 1240 \mathrm{~W} \\
\text { GAC filter column, EBCT } 20 \mathrm{~min}, \mathrm{pH} \approx 6.5-6.8\end{array}$ \\
\hline
\end{tabular}




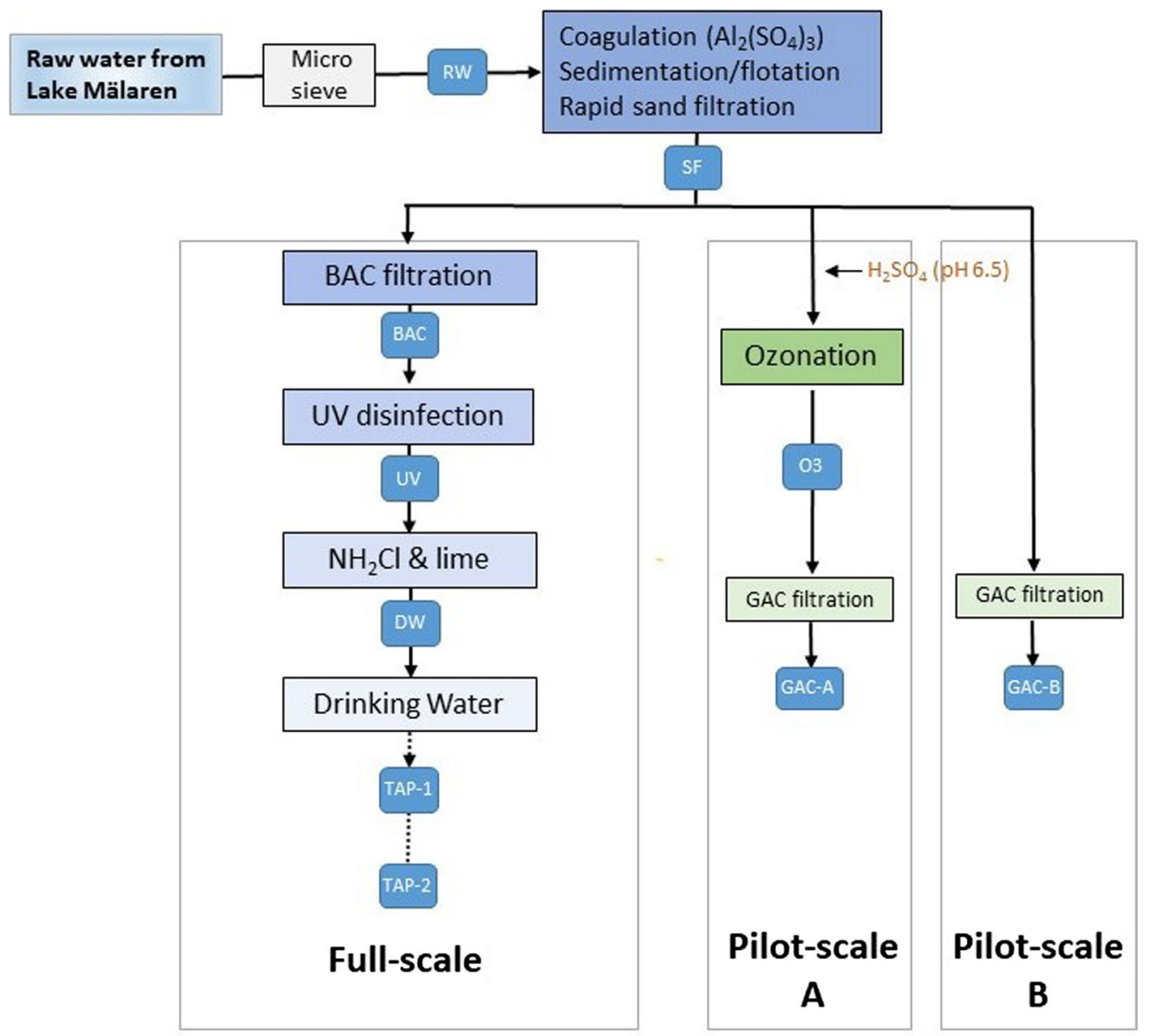

= Sampling location labelled with sample ID

Fig. 1 Treatment steps for the full-scale and the two pilot-scale treatment systems investigated at Görvälnverket (simplified diagram). The sampling points for all sampling events are indicated with symbols

\section{Sample collection}

Water samples were initially collected at the Görvälnverket DWTP in November 2019. Grab samples (approximately $5 \mathrm{~L}$ ) of water were collected from multiple points in both the full-scale and pilot-scale treatment systems (Table 1, Fig. 1). The water samples were collected in 12-L stainless steel (Sharpsville) containers and transported immediately back to the laboratory where they were stored at $-20{ }^{\circ} \mathrm{C}$ until sample preparation. Procedural controls included ultrapure water (Milli- $\mathrm{Q}^{\circledR}$ ) sourced from the laboratory.

Based on the results from the November 2019 samples, a follow-up sampling event was carried out in May 2020. The May 2020 sampling event targeted only the full-scale treatment system and one sample from the pilot-scale B system (the pilot-scale A system was no longer operational). An additional follow-up sampling event was conducted in September 2020 to determine if the bioactivities observed in the full-scale DWTP were persisting along the distribution network. As such, the September event focused only on the DWTP outlet as well as two consumer tap water sampling points along the distribution network, located approximately $6 \mathrm{~km}$ and $50 \mathrm{~km}$ from Görvälnverket. All repeat samples were collected from the same locations at Görvälnverket in all sampling events, then prepared and stored in the same manner.

\section{Sample preparation}

The extraction of the water samples $(5 \mathrm{~L})$ was conducted with an automatic solid-phase extraction system (SPEDEX 4790, Horizon Technology, Salem, NH, USA) using HLB extraction disks (Atlantic HLB-H Disks, diameter $47 \mathrm{~mm}$; Horizon Technology, Salem, NH, USA). 
Additional information regarding the sample preparations is provided in the Additional file 1: Section S1.

When incubated with the cells, the concentrated water samples were diluted 100 -fold with cell medium to get a final plate concentration of $1 \%$ ethanol to obtain a relative enrichment factor (REF) of 50 in the bioassays: 5000 (enrichment factor at SPE) $\times 0.01$ (dilution factor at bioassay). REF $>1$ denotes an enriched water sample and $\mathrm{REF}<1$ denotes a diluted water sample. The enrichment and dilution of the samples constitute the REF, as described by Escher et al. [19].

\section{Bioassays}

A summary of the bioassays is provided in Table 2 and more detailed descriptions of the bioanalytical methods and positive controls are provided in the Additional file 1: Section S1. The concentrated water samples along with procedural, vehicle, and positive controls were tested for Nrf2, AhR, ER, and AR agonist and antagonist activities in reporter gene assays. Genotoxicity was assessed using the in vitro mammalian cell micronucleus test (MCN) and analyzed with a MicroFlow Kit (Litron Laboratories, USA). Cytotoxicity was initially tested in all cell lines and defined as a cell viability of 0.8 compared to the vehicle control, set at 1 . For the MCN test, cytotoxicity was also assessed following the manufacturer's kit protocol (fourfold EMA-positive event increase over vehicle control). The main purpose of the cell viability testing was to ensure that the bioanalytical assessment of specific parameters was performed under non-cytotoxic conditions. Each sample was analyzed at the highest non-cytotoxic REF value.

As an initial screening, all water samples were analyzed for bioactivity at REF 50 in all bioassays. Each bioassay was conducted at least two times to prove biological reproducibility. This study presents the results from one of the representative experimental runs for each endpoint. In all assays except the MCN, samples showing bioactivity above the respective cut-off levels at REF 50 were then analyzed again in dilution series from REF 50 to REF 1.56 (dilution factor $=2$ ). As it has been suggested that activation of the Nrf2 pathway can also indirectly result in genotoxic effects [21, 22], the MCN test was performed on samples that displayed Nrf2 activity above the cut-off. In all experimental runs, four technical replicates for each sample were tested. In each reporter gene assay, reference compounds (positive controls) were analyzed in parallel with the water samples. The positive controls were analyzed in 6-12 concentrations to obtain standard curves. The compounds used in each assay are listed in Table 2 and described further in the Additional file 1: Section S1.

\section{Data evaluation}

Bioactivities observed in the initial screening at REF 50 were expressed as fold change normalized to the vehicle controls, set to 1 in all assays except the MCN. In the $\mathrm{MCN}$ assay, the genotoxicity of the water samples was assessed by comparing the micronuclei formation rates (\%) to that in the vehicle control. For Nrf2, where no maximum effect can be reached, the standard curve for the reference compound was based on a linear regression of activities normalized to the mean activity of the vehicle control. For AhR, AR, and ER, the standard curves for the reference compounds were obtained by fitting data to a four-parameter sigmoidal curve fit.

For the dilution series, concentration-effect curves (CECs) were obtained from the dilution series for those samples that showed bioactivity above the respective cutoff levels at REF 50. CECs were fit to a four-parameter

Table 2 Summary of the applied bioanalytical methods

\begin{tabular}{|c|c|c|c|c|c|}
\hline Biological effect & Cellular endpoint & Cell line & $\begin{array}{l}\text { Reference compound/ } \\
\text { positive control }\end{array}$ & LOD (fold change) & $\begin{array}{l}\text { Cut-off } \\
\text { (fold } \\
\text { change) }\end{array}$ \\
\hline Adaptive stress response & $\begin{array}{l}\text { Oxidative stress response } \\
\text { (Nrf2 activity) }\end{array}$ & MCF7AREC32 & $\mathrm{tBHQ}(0.78-50 \mu \mathrm{M})$ & $1.31-1.40$ & 1.5 \\
\hline Reactivity & $\begin{array}{l}\text { Genotoxicity (micronuclei } \\
\text { formation) }\end{array}$ & TK6 & Mitomycin C (100 nM) & - & * \\
\hline Xenobiotic metabolism & $\begin{array}{l}\text { Aryl hydrocarbon receptor } \\
\text { activation }\end{array}$ & DR-EcoScreen & TCDD (0.5-1000 pM) & $1.12-1.50$ & 1.5 \\
\hline \multirow[t]{3}{*}{$\begin{array}{l}\text { Modulation of hormone } \\
\text { systems }\end{array}$} & Estrogen receptor agonism & VM7Luc4E2 & $\begin{array}{l}\text { 17ß-estradiol (0.358- } \\
367.1 \mathrm{pM})\end{array}$ & $1.56-1.70$ & 2.0 \\
\hline & Androgen receptor agonism & AR-EcoScreen GR KO M1 & DHT (0.001-1000 nM) & $1.20-1.50$ & 1.5 \\
\hline & $\begin{array}{l}\text { Androgen receptor antago- } \\
\text { nism }\end{array}$ & AR-EcoScreen GR KO M1 & OHF $(0.01-10,000$ nM) & $0.76-0.88$ & 0.70 \\
\hline
\end{tabular}

*Genotoxicity was determined as statistical significance of micronuclei formations compared to that in the vehicle control $(p<0.05)$ 
sigmoidal curve fit for the reference compounds. For all data sets, the mean activity of the vehicle control was first subtracted from all replicates. All adjusted values were then normalized first to the mean activity of the vehicle control, then to the percent of maximum activity of the reference compound. For AhR and ER, linear regression was performed on the normalized data with $y$-axis intercept fixed at zero and the estimated slope from the regression was used to determine the concentration causing $10 \%$ effect (EC10) expressed as REFs, as proposed by Escher et al. [23]. As there is no clear maximum response for Nrf2 activity, fold inductions were normalized to that of the vehicle control then fitted to a linear regression model. The concentration, expressed as REF, causing a 1.5-fold induction $\left(\mathrm{EC}_{\mathrm{IR} 1.5}\right)$ was estimated from the model. The EC values for all samples are provided in the Additional file 1: Table S2. All statistical analyses as well as graphical presentations were performed using GraphPad Prism (version 8.3.0).

For Nrf2 activity, a fold induction of 1.5 compared to the normalized vehicle control was used as the cut-off level for bioactivity, as recommended by Escher et al. [21]. For AhR, AR, and ER, cut-off levels for bioactivity were based on the limit of detection (LOD) for that assay, which was defined as 1 plus 3 times the standard deviation (SD) of the normalized vehicle control [21]. A cut-off level for a positive response was then set for each assay as a value exceeding the LOD value. In instances when the LOD was below 1.5, the cut-off level was set to 1.5 , and if the LOD was between 1.5 and 2, the cut-off level was set at 2. For AR antagonist activity, the LOD was calculated as 1 minus 3 times the SD of the normalized vehicle control, and a cut-off level of 0.7 was set. For genotoxicity, statistical significance from the vehicle control was assessed in place of a cut-off level, following the guidance in the OECD's TG487 acceptability [24]. A summary of the bioassays and concentration ranges of the reference compounds is provided in Table 2.

For the Nrf2, AhR, AR, and ER assays, $\mathrm{EC}_{\mathrm{IR} 1.5}$ and $\mathrm{EC}_{10}$ values were used to convert the bioactivities measured in the samples into biological equivalent concentrations (BEQs) of the respective positive controls using the following Eq. (1) adapted from Jia et al. [25]:

$$
\mathrm{BEQ}_{\text {bio }}=\frac{\left(\mathrm{EC}_{10} \text { or } \mathrm{EC}_{\text {IR1.5 }}\right)_{\text {positive control }}}{\left(\mathrm{EC}_{10} \text { or } \mathrm{EC}_{\text {IR1.5 }}\right)_{\text {sample }}} \text {. }
$$

To account for differences in sensitivity in the experimental runs between November, May, and September, the $\mathrm{BEQ}$ values were calculated to enable comparisons of the data sets between the three sampling events. Based on the BEQ values, the removal efficacies could then be compared to each other.
For the MCN assay, the results in each sampling event were compared to the vehicle control using a one-way ANOVA comparison followed by Dunnett post hoc test. Genotoxicity was defined as a statistically significant increase in the number of micronuclei (\% micronuclei events) compared to the vehicle control. $P$-values less than 0.05 were considered statistically significant. To determine if the results could be compared between the three sampling events, a multiple comparison test of the positive control (Mitomycin C) data was first conducted. No significant differences between the mean \% micronuclei events across all three sampling events were detected (Additional file 1: Fig. S7). The statistical analysis and graphical presentations were performed using GraphPad Prism (version 8.3.0).

\section{Results and discussion Cell viability}

All samples were initially tested for cytotoxicity at REF 50 in all assays. In the Nrf2, AhR, ER, and AR assays, none of the water samples exerted cytotoxicity, defined as cell viability below 0.8 compared to vehicle control (Additional file 1: Fig. S1). This demonstrated that the bioassays were conducted under conditions where the cell viability was not compromised. For the MCN assay, no cytotoxicity as defined by the manufacturer's kit protocol (fourfold EMA-positive event increase over vehicle control) was observed in any of the samples at the highest REF value of 50 (Additional file 1: Fig. S8).

\section{Initial screening of pilot- and full-scale samples}

In the samples from November 2019, we observed Nrf2, AhR, and ER activities above cut-off levels at REF 50 and statistically significant genotoxic activities in the incoming raw water (Fig. 2A, D, G; Fig. 3A). Further, the Nrf2, $A h R$ and genotoxic activities increased after the initial coagulation and sand filtration step. In general, the activities were not decreased to below cut-off levels by the coagulation and SF, BAC or UV treatments. The finished drinking water after dosing with monochloramine, on the other hand, was inactive in all four assays. In the pilotscale systems, both ozonation and GAC filtration considerably reduced the observed bioactivities to below the respective cut-off levels across all assays.

In the follow-up sampling in May 2020, the Nrf2 activities at REF 50 in the incoming raw water were lower than in November. Again, none of the treatment steps in the full-scale system reduced the bioactivities, except the reduction of genotoxic activity after monochloramine dosing. The pilot-scale GAC-B system, on the other hand, reduced all the activities to or below the cut-offs (Fig. 2B, $\mathrm{E}, \mathrm{H}$; Fig. 3B). The highest reduction following the GAC treatment was a 2.3-fold decrease in AhR activity. This 


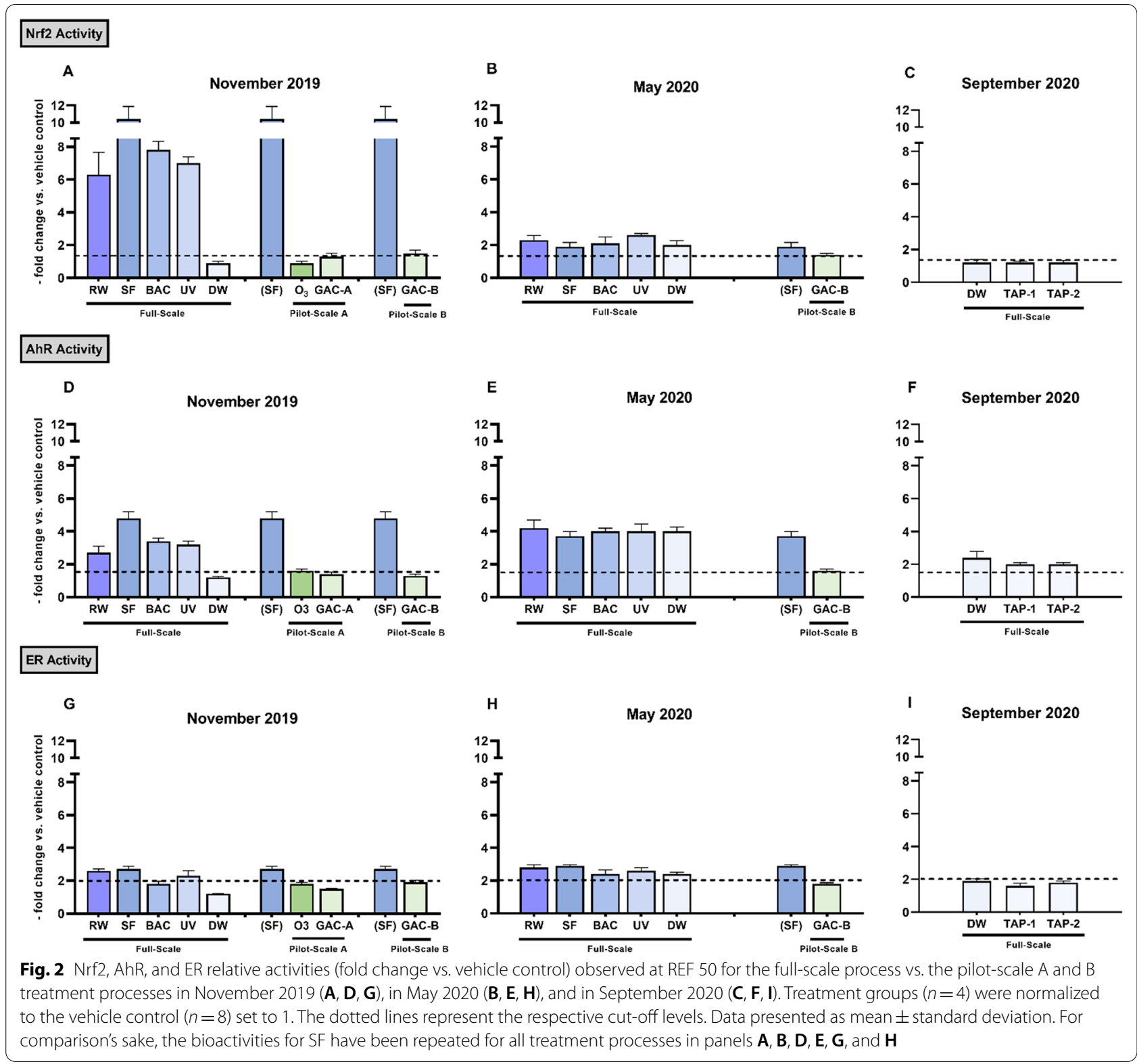

indicates that, even after being in operation for nearly 2 years, adsorption properties in this filter still remain, as the filter performed better when compared to the fullscale BAC. Alternatively, there may be beneficial effects from the longer $\mathrm{EBCT}$ in the pilot filter.

In September 2020, an additional sampling event was carried out to specifically study the outgoing drinking water and two tap locations in the distribution network. AhR activity at REF 50 above cut-off (Fig. 2F) and genotoxicity (Fig. 3C) were observed. However, genotoxicity was not detected in the two samples from the distribution network indicating that removal or transformation of micropollutants may have occurred during distribution.
As an additional step in the data interpretation, to compare differences in bioactivities between each of the treatment steps, results were statistically evaluated using a one-way ANOVA comparison followed by Dunnett post hoc test, performed in GraphPad Prism (version 8.3.0). A table summarizing the statistical analysis is provided in the Additional file 1: Table S1. Neither androgenic nor anti-androgenic activities were observed in any sample across all sampling events. The results are presented in the Additional file 1: Fig. S9.

In summary, the removal efficiencies of the treatment steps in the full-scale system varied between the sampling events and most treatments showed little or no 

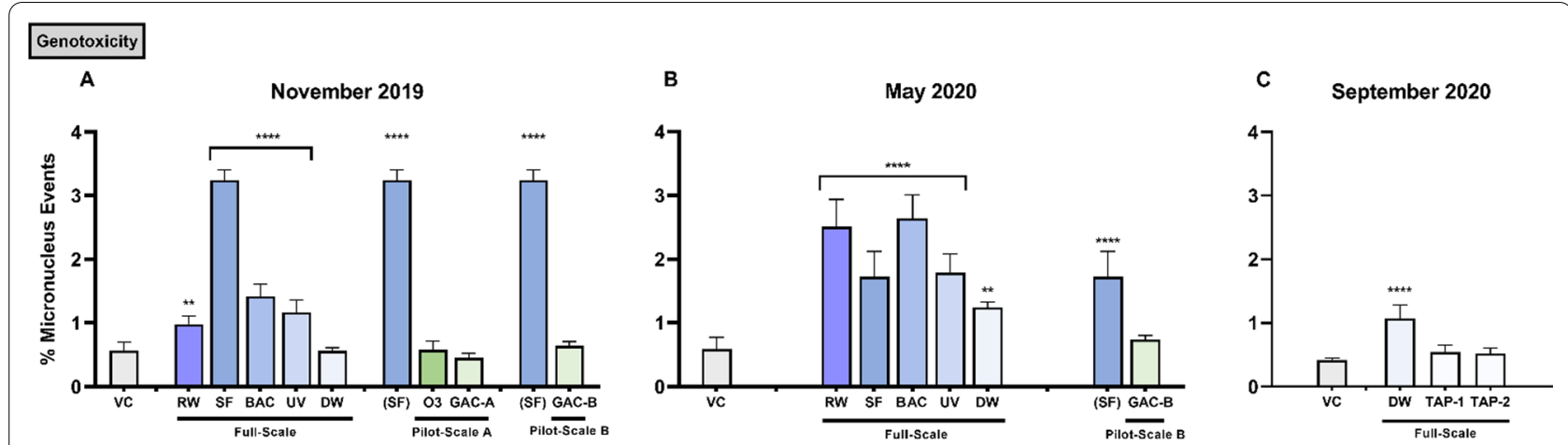

Fig. 3 Micronuclei formation rates at REF 50 from the full-scale process vs. the pilot-scale A and B treatment processes in November 2019 (A), in May 2020 (B), and in September 2020 (C). Treatment groups $(n=4)$ were compared to the vehicle control $(n=8)$. Data presented as mean \pm standard deviation. ${ }^{*}$ represents significant differences from the vehicle control $\left({ }^{*} p \leq 0.05,{ }^{* *} p \leq 0.01,{ }^{* * *} p \leq 0.001,{ }^{* * *} p \leq 0.0001\right)$. For comparison's sake, the micronuclei formation rate for SF has been repeated for all treatment processes in panels $\mathbf{A}$ and $\mathbf{B}$

effect on the bioactivities detected in the incoming water. Both ozone and GAC in the pilot-scale systems, on the other hand, effectively reduced observed Nrf2, AhR, and ER activities to or below the cut-off levels and to no statistically significant inductions compared to the vehicle control for genotoxic activities. In general, ozonation treatment is likely to continuously provide a decrease in observed activities. GAC filtration, particularly without pre-ozonation, will likely require regular regeneration to maintain its removal capabilities. However, our results indicate that for an EBCT of 20 min, regeneration may not be needed until after more than 2 years of running time. As the ozonation appeared to remove all activities to levels below the cut-off in the pilot-scale A system, it would suggest that regeneration of the subsequent GAC in the combined treatment would not be needed. However, a biofilter step would still be needed downstream of ozonation to obtain biostability.

Bioactive samples, defined as above the respective cutoff levels at REF 50, were also analyzed in dilution-series (Additional file 1: Figs. S3 to S5) in order to determine effect concentrations (ECs) and bioequivalent concentrations (BEQs). These results are discussed in further detail below.

\section{Seasonal differences in bioactivities between sampling events}

We observed seasonal differences in the bioactivities in the raw water samples between the November and May sampling events. For Nrf2, the activity was noticeably higher (8.4 times) in November than May based on the BEQ values (Table 3); while the AhR activity was higher in May than November, albeit by only 1.8 times. Further, the genotoxicity was higher in the raw water in May than in November (Fig. 3). These inconsistent bioactivities across the sampling events can be attributed to the fact that temporal variation in the quality and micropollutant profile of source water is expected to occur. Such factors have been discussed in other DWTP studies which also reported seasonal/temporal variations for similar endpoints such as Nrf2 activity [26, 27], AhR and androgenic activities [28], and genotoxicity [29-32]. For instance, Hebert et al. [26] measured Nrf2 activities in water samples collected from the outlets of three DWTPs in France across several sampling events (November 2015 and March, May, September 2016). The DWTPS used a combination of clarification, sand filtration, ozonation, GAC filtration, and UV. They reported higher Nrf2 activities in May and September compared to November and March for all three DWTPs, likely due to higher levels of some DBPs in September as a result of warmer temperatures. In our study, the highest Nrf2 activity was detected in November. Based on monitoring data provided by Norrvatten, the temperature of the incoming raw water was slightly higher in November 2019 than in May 2020. Hebert et al. [26] also speculated that the increased effect seen in September may be due to the formation of undetected non-volatile or semi-volatile DBPs or due to other existing micropollutants in the source water. Further, treatment processes could increase effects such as genotoxicity in the water and genotoxic dissolved organic matter might be released or formed during purification processes [32]. Other possible influences may be related to interactions with organic matter [33] and the biostability of the water [34], the presence of natural toxins [35] in the raw water, or the formation of transformation products during a treatment process [36]. In our study, it could thus be hypothesized that the compositions of bioactive compounds present in the samples were different between the sampling events, due to temporal variations 


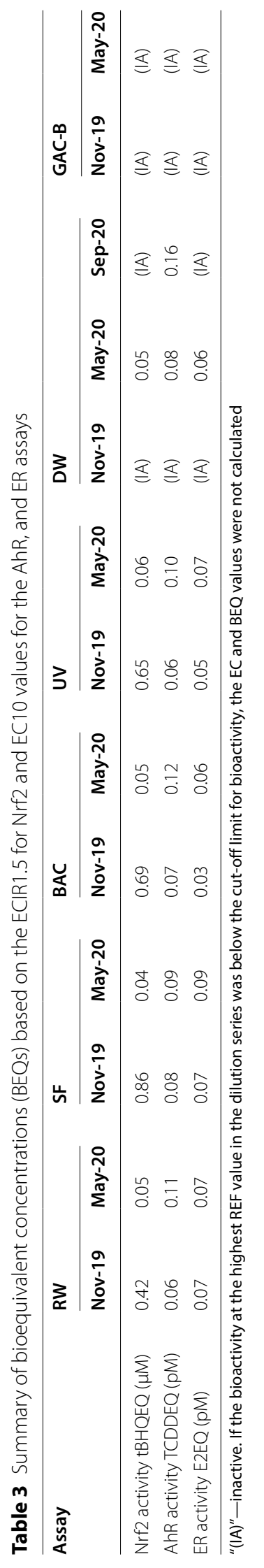


in the incoming source water, and that these different causative compounds are not equally responsive to the different treatment technologies used.

\section{Discussion on pilot-scale treatment technologies}

This study highlights the efficacy of ozonation and GAC filtration in removing bioactive and genotoxic compounds compared to the full-scale treatments. For instance, the tBHQEQ was decreased from $0.86 \mu \mathrm{M}$ (November) and $0.04 \mu \mathrm{M}$ (May) in the primary-treated (SF) water entering the pilot-scale GAC-B system to below the cut-off for Nrf2 activity following GAC filtration alone in both sampling events. Similarly, the E2EQ in the SF-treated water was reduced to below the cutoff for estrogenic activity from $0.07 \mathrm{pM}$ in November and $0.09 \mathrm{pM}$ in May. For AhR activity, the TCDDEQ in the SF-treated water decreased from 0.08 pM (November) and $0.09 \mathrm{pM}$ (May) to below the cut-off following GAC filtration alone. Similarly, Nrf2, AhR, ER bioactivities and micronuclei formations were all lower at REF 50 in the $\mathrm{O}_{3}$ and GAC-A treated samples collected in November compared to the incoming water following the initial coagulation and rapid sand filtration step. It is worthwhile to mention that the performance of the pilotscale systems at removing OMPs was previously tested in a 1-year pilot-scale study between May 2018 and July 2019, alongside the full-scale system [8]. The lowest levels of OMPs were observed in GAC effluents from ozonated feed water demonstrating the efficacy of combining ozone with GAC for managing OMP levels [8]. Similar to the observation made in this study regarding the efficiency of the pilot-scale ozonation treatment, Jia et al. [25] reported that ozone technology was able to significantly remove Nrf2 activity (AREc32) with BEQ reduction values between 60 and $80 \%$. While BEQ values for the pilot-scale ozonation were not determined in this study, the fact that Nrf2 activities at REF50 decreased to below cut-off following ozonation suggests high BEQ reduction. In another study, Shi et al. [37] reported higher overall treatment efficiencies in removing genotoxic, mutagenic, dioxin-like and estrogenic pollutants at DWTPs that used primary treatment methods coupled with ozone-activated carbon similar to Görvalnverket vs. those DWTPs that did not include ozone-activated carbon.

Other studies based on chemical profiling of the water samples have reported the efficacy of ozonation and GAC filtration in removing micropollutants [7] as well as NOM and precursors of DBPs products [7, 38-42]. As well, the efficacy of GAC filtration (from a DBP perspective) has been reported elsewhere [43] and at other Swedish DWTPs $[4,15]$. Also, ozonation alone has been shown to be an effective treatment for antibiotics [31] and estrogenic chemicals [44-46]. The estrogenic activities of $17 \alpha$-ethinylestradiol and bisphenol A, for instance, dramatically decreased following ozonation treatment in a MCF-7 cell proliferation assay [46]. In the ER $\alpha$ CALUX bioassay, the combination of coagulation, sedimentation, sand filtration and chlorination with ozone-activated carbon adsorption was shown to efficiently remove estrogenic potentials from source water better than coagulation, sedimentation, sand filtration and chlorination alone [37]. GAC filtration alone has also been shown to remove more organic compounds, including pharmaceuticals and steroids, than disinfection with sodium hypochlorite or clarification [47].

However, the age of the respective treatment technologies should also be considered when comparing removal performances. In the case of the full-scale BAC vs. the pilot-scale GAC, for instance, it would be worthwhile to compare their effectiveness based on the age range and treated bed volumes of the filter units given that the effectiveness of a filter will likely decrease with time as the filter ages [48]. In an earlier study, Cuthbertson et al. [43] reported that calculated cytotoxicity and genotoxicity were considerably lower following GAC treatment at younger service lives. Further, an increase in GAC run time resulted in an increase of DBPs under simulated distribution system conditions which corresponded to increased calculated cytotoxicity and genotoxicity. The toxicity in their study was determined by the TIC-Tox method. The age and regeneration frequency of a GAC is essential for its function as a chemical barrier. The GAC in the full-scale system has been operating for over 10 years and is currently functioning as a BAC. In comparison, the GAC filters of the pilot-scale systems were installed in May 2018. As such, the dynamics of a GAC filter in its function as either an adsorption filter (GAC) or a biological filter (BAC) can represent two very different removal processes and capabilities. Nevertheless, both ozonation and GAC filtration or GAC filtration alone show great promise as barriers against bioactive compounds in drinking water production [8] and in the overall reduction of DBP formations [43]. Similar observations have been demonstrated elsewhere [15, 49].

\section{Discussion on full-scale treatment technologies}

In November, Nrf2, AhR, and genotoxic activities measured in the incoming raw water increased following the initial coagulation and rapid sand filtration steps (Fig. 2; Table 3). The tBHQEQ and TCDDEQ were approximately 2 and 1.3 times higher, respectively, following the conventional coagulation treatment. In the ER assay, the estrogenic activity remained comparable after this initial treatment step. Taken together, the results suggest there was little or no removal effect following this primary 
treatment step of the full-scale system. Other studies have reported that chemical precipitation processes using coagulants like aluminum sulfate, which is used at Görvälnverket, result in minimal removal of most endocrine-disrupting compounds (EDCs) [45, 50].

Overall, most of the remaining treatments in the fullscale system did not reduce the bioactivities to below cutoff levels across both sampling events, except for BAC in the ER assay and monochloramine dosing in all assays in November. The lack of treatment effects is also reflected in the relatively low BEQ reduction values between these treatment steps, observed for multiple toxicity endpoints. For Nrf2 activity, the highest BEQ reduction value achieved was 20\% (SF in May), while the highest BEQ reduction value for AhR activity was $18.2 \%$ (SF in May). Rosenmai et al. [16] had previously conducted a bioanalytical study at Görvälnverket and reported findings similar to our observations in May wherein the coagulation treatment, GAC filtration, UV disinfection, and monochloramine dosing of the full-scale system did not decrease Nrf2, AhR, or ER activities. Also consistent with our results of little treatment effect, Lundqvist et al. [17] reported almost similar activities in the inlet $(53 \mathrm{ng} / \mathrm{L}$ TCDDEQ) and outlet samples (45-52 ng/L TCDDEQ) collected from a DWTP that employed treatments similar to Görvälnverket (e.g., coagulation, sedimentation, rapid then slow sand filtration, $\mathrm{UV}, \mathrm{NH}_{2} \mathrm{Cl}$ dosing) in the AhR reporter gene assay. As well, Macova et al. [51] reported no change in activities in the AhR CAFLUX assay between the inlet and outlet samples from a DWTP that used coagulation, flocculation, sedimentation, filtration, and chlorination.

On the other hand, Escher et al. [21] reported higher $\mathrm{Nrf2}$ activities in AREc32 cells in water samples from the outlet $\left(4.16 \times 10^{4} \mathrm{ng} / \mathrm{L}\right.$ tBHQEQ $)$ compared to the inlet $\left(1.83 \times 10^{4} \mathrm{ng} / \mathrm{L} \mathrm{tBHQEQ}\right)$ of a DWTP that utilized treatments similar to at Görvälnverket (e.g., coagulation, flocculation, sedimentation, filtration, chlorination). The authors attributed the increase to the formation of DBPs as a result of chlorination.

As well, in a recent bioanalytical study that investigated multiple DWTPs, Oskarsson et al. [15] reported better treatment effects at two Swedish DWTPs that employed treatment trains similar to that at Görvälnverket (e.g., rapid sand filtration, GAC, UV irradiation, chlorination). At those two DWTPs, AhR activities were reduced from 31 and 34 pM TCDDEQ at the inlets to below cut-off at the outlets.

In available literature investigating genotoxicity of finished drinking water samples, conflicting results have been reported. For instance, some studies investigating the genotoxicity in drinking water samples observed decreases in micronuclei inductions following various conventional water treatment methods similar to those employed at Görvälnverket [37, 52]. Several other studies using different established cell lines reported no significant differences in the frequency of micronucleus events between control samples and samples representing conventional treatment methods (e.g., pre-disinfection with chlorine dioxide, coagulation, sand- and GAC-filtration, post-chlorination), therefore suggesting no treatment effects [29, 53-55].

In November, the full-scale BAC filtration and monochloramine secondary disinfection appeared to reduce estrogenic activities, albeit low estrogen activities were detected overall; however, in May there appeared to be little treatment effect. Neale et al. [27] studied two DWTPs that employ similar treatment sequences: (preozonation), clarification, sand filtration, ozonation, GAC, and then UV treatment followed by chlorination. In their study, estrogenic activity was detected in all source water samples as well; however, the treatment processes reduced the activity to below the limit of detection. As discussed above, ozonation has been shown to reduce estrogenic chemicals.

With respect to the September sampling event focused on the finished drinking water and the distribution network, passage through the distribution network appeared to reduce genotoxic activity. Removal of bioactivities in water samples collected from Görvälnverket's distribution network had previously been reported [16]. It has been suggested that decreasing bioactivities along a distribution network could be due to the binding of bioactive compounds to the pipe surface or the biofilm, or the degradation/inactivation of the compounds by microorganisms present in the biofilm [56]. As such, the removal of genotoxic activity in the distribution network in the present study may be explained by interactions between genotoxic compounds and the biofilm.

Regarding the lack of AR activity observed in the current study, similar results were reported by Rosenmai et al. [16] from Görvälnverket and in other countries wherein the activation or inhibition of AR was not commonly detected [27, 28, 57-61]. Further, AR antagonistic activity was detected in drinking water from other DWTPs in Sweden [15]. Still, AR agonistic activity has also been reported in treated water [62].

\section{Conclusions}

In this study, we observed oxidative stress, genotoxicity, AhR, and ER agonist activities in raw water used for drinking water production over the course of repeated sampling events. In general, most of the full-scale treatment methods were unable to fully remove the compounds causing these activities. On the other hand, pilot-scale treatment with either ozonation or GAC 
filtration was more efficient in removing the compounds causing oxidative stress, genotoxicity, AhR and ER agonist induction. Both treatment methods appeared to perform better than the conventional full-scale treatment methods utilized at this subject DWTP.

The variability in treatment effects in the full-scale system observed in this study, which has also been reported in other studies on similar treatment technologies, suggests that the treatment process as well as the characteristics of the source water are important factors when assessing the toxic potential of treatment-processed drinking water. Another important consideration is the seasonal variation in the quality of the raw water in that the physico-chemical profile of the incoming water (e.g., temperature, organic matter, micropollutant profile) would differ between sampling events which could be linked to different reactivities during the treatment processes.

Using a panel of cell-based bioassays, this study highlighted that ozonation and GAC filtration methods are effective at reducing bioactivities. The study also demonstrated the usefulness of conducting a pilot-scale assessment combined with bioanalytical methods as a valuable approach to test water treatment techniques before fullscale implementation. As such, the conclusions made in this study regarding both the pilot-scale and full-scale drinking water treatment methods provide important insights into the optimization of existing drinking water treatment designs and support the need for further research into the removal of micropollutants in drinking water. The findings of this study thus suggest that micropollutant removal appears to be dependent on the treatment type, season, and quality of the source water.

Further work with this study could include: chemical analyses and an effect-based analysis (EDA) of the water samples to identify the causative compounds of the observed biological effects; composite sampling over a longer time period in a day; and cost-benefit analysis of the pilot-scale systems. The results of this study will hopefully contribute to the growing body of research supporting more efficient implementation of bioanalytical tools into operational practices at DWTPs, water safety planning, and incorporation into more comprehensive regulatory frameworks for water quality monitoring. Lastly, while the focus of this study was on drinking water treatments, it would be remiss to not also mention environmental implications. Given that source waters of DWTPs are often impacted by human activities, it can be hypothesized that the effects observed in this study are likely attributed to environmental pollutants. Implications such as this draw evidence-based attention towards the need to improve the management and protection of our water resources.

\section{Abbreviations}

AhR: Aryl hydrocarbon receptor; AR: Androgen receptor; BAC: Biologically activated carbon; BEQ: Biological equivalent concentration; CEC: Concentration effect curve; DBP: Disinfection by-product; DWTP: Drinking water treatment plant; EBCT: Empty bed contact time; EC: Effect concentration; ER: Estrogen receptor; GAC: Granular activated carbon; HAAs: Haloacetic acids; LOD: Limit of detection; MCN: Micronucleus; NOM: Natural organic matter; $\mathrm{O}_{3}$ : Ozonation; OMP: Organic micropollutant; REF: Relative enrichment factor; SD: Standard deviation; SPE: Solid-phase extraction; THMs: Trihalo-methanes; UV: Ultraviolet.

\section{Supplementary Information}

The online version contains supplementary material available at https://doi. org/10.1186/s12302-021-00567-y.

Additional file 1: Section S1. Detailed information on sample preparation. Section S2. Detailed information on bioassays and analysis.

Table S1. ANOVA and post hoc Dunnett comparisons of mean bioactivities measured at REF50 in each treatment step in the Nrf2, AhR, and ER assays. Table S2. ECIR1.5 (Nrf2) and EC10 (AhR, ER) values of the water samples expressed as REF. Figure S1. Cell viabilities for MCF7AREC32, DR EcoScreen, and AR EcoScreen GR-KO were analyzed by MTS activity and by ATPase activity for VM7Luc4E2. Figure S2. Standard curves for the positive controls in the Nrf2 (tBHQ), AhR (TCDD), and ER (E2) assays from the initial screening assays tested at REF50 for each sampling event. Figure S3. Concentration-effect curves for Nrf2-active samples in November 2019, May 2020, and September 2020. Figure S4. Concentration-effect curves for AhR-active samples in November 2019, May 2020, and September 2020. Figure S5. Concentration-effect curves for ER-active samples in November 2019, May 2020, and September 2020. Figure S6. Standard curves for the positive controls in the Nrf2 (tBHQ), AhR (TCDD), and ER agonist (E2) assays in the dilutions series for each sampling event. Figure S7. Comparison of micronuclei formations from the positive control at REF 50 across all three sampling events. Figure S8. Cytotoxicity for select samples $(n=4)$ from the full- and pilot-scale treatment systems analyzed at REF 50 in November 2019, May 2020, and September compared to the vehicle control $(n=8)$. Figure S9. AR agonist and antagonist activities (fold change vs. vehicle control) observed at REF 50 for the full-scale process vs. the pilot-scale A and B treatment processes in November 2019), in May 2020, and in September 2020. Figure S10. Standard curves for the positive controls in the AR agonist (DHT) and antagonist (OHF) assays from the initial screenings at REF50 for each sampling event.

\section{Acknowledgements}

The authors would like to thank the Department of Aquatic Sciences and Assessment, Swedish University of Agricultural Sciences (SLU) for assistance with the sample preparations. Helene Ejhed and Daniel Hellström at Norrvatten and Görvälnverket are acknowledged for their assistance during the sample collections and advice during the project and valuable comments on the manuscript.

\section{Authors' contributions}

$J \mathrm{~L}$ and MY planned the study project. $J \mathrm{~L}$ coordinated the collaborations. MY conducted the sampling, experiments, and data handling. JL, AO, and $E L$ supervised the findings of the study. MY wrote the manuscript with input from all authors. JL, AO, and EL provided critical feedback and helped shape the manuscript. All authors read and approved the final manuscript.

\section{Funding}

Open access funding provided by Swedish University of Agricultural Sciences. The research was supported by the Swedish Research Council Formas (Grants Number 2018-00386, 2018-02256 and 2019-02043).

\section{Availability of data and materials}

The datasets used and/or analyzed during the current study are available from the corresponding author on reasonable request. 


\section{Declarations}

Ethics approval and consent to participate

Not applicable.

\section{Consent for publication}

Not applicable.

\section{Competing interests}

The authors declare the following financial interests/personal relationships which may be considered as potential competing interests: J.L. and A.O. are the founders and owners of BioCell Analytica Uppsala AB, a company providing effect-based testing services to the water sector.

\section{Author details}

${ }^{1}$ Department of Biomedical Sciences and Veterinary Public Health, Swedish University of Agricultural Sciences, Box 7028, 75007 Uppsala, Sweden. Veolia Water Technologies, Vretenvägen 9, 17154 Solna, Sweden. ${ }^{3}$ Norrvatten, Quality and Development, 16902 Solna, Sweden.

Received: 6 August 2021 Accepted: 23 October 2021

Published online: 08 November 2021

\section{References}

1. Calderon RL (2000) The epidemiology of chemical contaminants of drinking water. Food Chem Toxicol 38:S13-S20

2. Global Water Research Coalition (2020) Effect based monitoring in water safety planning WP3.2: medium-to-high throughput bioanalytical tools and decision-making tool for selection of bioassays. London

3. Villanueva CM, Kogevinas M, Cordier S, Templeton MR, Vermeulen R, Nuckols JR, Nieuwenhuijsen MJ, Levallois P (2014) Assessing exposure and health consequences of chemicals in drinking water: current state of knowledge and research needs. Environ Health Perspect 122:213-221

4. Tröger R, Klöckner P, Ahrens L, Wiberg K (2018) Micropollutants in drinking water from source to tap-method development and application of a multiresidue screening method. Sci Total Environ 627:1404-1432

5. American Water Works Association (AWWA) (2021) Emerging trends in disinfection: lessons from AWWA's disinfection survey. J AWWA. https:// doi.org/10.1002/awwa.1648

6. Ngwenya N, Ncube EJ, Parsons J (2013) Recent advances in drinking water disinfection: successes and challenges. Rev Environ Contam Toxicol 222:111-170

7. Kim KS, Oh BS, Kang JW, Chung DM, Cho WH, Choi YK (2005) Effect of ozone and GAC process for the treatment of micropollutants and DBPs control in drinking water: pilot scale evaluation. Ozone Sci Eng 27:69-79

8. Ullberg M, Lavonen E, Köhler SJ, Golovko O, Wiberg K (2021) Pilot-scale removal of organic micropollutants and natural organic matter from drinking water using ozonation followed by granular activated carbon. Environ Sci Water Res Technol 7:535-548

9. Brack W, Aissa SA, Backhaus T et al (2019) Effect-based methods are key. The European Collaborative Project SOLUTIONS recommends integrating effect-based methods for diagnosis and monitoring of water quality. Environ Sci Eur 31:10

10. De Baat ML, Kraak MHS, Van der Oost R, De Voogt P, Verdonschot PFM (2019) Effect-based nationwide surface water quality assessment to identify ecotoxicological risks. Water Res 159:434-443

11. Dopp E, Pannekens H, Itzel F, Tuerk J (2019) Effect-based methods in combination with state-of-the-art chemical analysis for assessment of water quality as integrated approach. Int J Hyg Environ Health 222:607-614

12. Escher Bl, Aït-Aïssa S, Behnisch PA et al (2018) Effect-based trigger values for in vitro and in vivo bioassays performed on surface water extracts supporting the environmental quality standards (EQS) of the European Water Framework Directive. Sci Total Environ 628-629:748-765

13. Escher BI, Stapleton HM, Schymanski EL (2020) Tracking complex mixtures of chemicals in our changing environment. Science (80-) 367:388-392

14. Neale PA, Altenburger R, Aït-Aïssa S et al (2017) Development of a bioanalytical test battery for water quality monitoring: fingerprinting identified micropollutants and their contribution to effects in surface water. Water Res 123:734-750

15. Oskarsson A, Rosenmai AK, Mandava G, Johannisson A, Holmes A, Tröger R, Lundqvist J (2021) Assessment of source and treated water quality in seven drinking water treatment plants by in vitro bioassays-oxidative stress and antiandrogenic effects after artificial infiltration. Sci Total Environ 758:144001

16. Rosenmai AK, Lundqvist J, le Godec T, Ohlsson Å, Tröger R, Hellman B, Oskarsson A (2018) In vitro bioanalysis of drinking water from source to tap. Water Res 139:272-280

17. Lundqvist J, Mandava G, Lungu-Mitea S, Lai FY, Ahrens L (2019) In vitro bioanalytical evaluation of removal efficiency for bioactive chemicals in Swedish wastewater treatment plants. Sci Rep 9:7166

18. Dingemans MML, Baken KA, van der Oost $R$, Schriks M, van Wezel AP (2019) Risk-based approach in the revised European Union drinking water legislation: opportunities for bioanalytical tools. Integr Environ Assess Manag 15:126-134

19. Escher $\mathrm{Bl}$, Allinson $\mathrm{M}$, Altenburger $\mathrm{R}$ et al (2014) Benchmarking organic micropollutants in wastewater, recycled water and drinking water with in vitro bioassays. Environ Sci Technol 48:1940-1956

20. Rehrl A-L, Golovko O, Ahrens L, Köhler S (2020) Spatial and seasonal trends of organic micropollutants in Sweden's most important drinking water reservoir. Chemosphere 249:126168

21. Escher BI, Dutt M, Maylin E, Tang JYM, Toze S, Wolf CR, Lang M (2012) Water quality assessment using the AREc32 reporter gene assay indicative of the oxidative stress response pathway. J Environ Monit 14:2877

22. Van der Linden SC, von Bergh ARM, van Vught-Lussenburg BMA, Jonker LRA, Teunis M, Krul CAM, van der Burg B (2014) Development of a panel of high-throughput reporter-gene assays to detect genotoxicity and oxidative stress. Mutat Res Toxicol Environ Mutagen 760:23-32

23. Escher BI, Neale PA, Villeneuve DL (2018) The advantages of linear concentration-response curves for in vitro bioassays with environmental samples. Environ Toxicol Chem 37:2273-2280

24. OECD (2016) Test No. 487: in vitro mammalian cell micronucleus test. https://doi.org/10.1787/9789264264861-en

25. Jia A, Escher BI, Leusch FDL, Tang JYM, Prochazka E, Dong B, Snyder EM, Snyder SA (2015) In vitro bioassays to evaluate complex chemical mixtures in recycled water. Water Res 80:1-11

26. Hebert A, Feliers C, Lecarpentier C, Neale PA, Schlichting R, Thibert S, Escher BI (2018) Bioanalytical assessment of adaptive stress responses in drinking water: a predictive tool to differentiate between micropollutants and disinfection by-products. Water Res 132:340-349

27. Neale PA, Feliers C, Glauch L, König M, Lecarpentier C, Schlichting R, Thibert S, Escher BI (2020) Application of in vitro bioassays for water quality monitoring in three drinking water treatment plants using different treatment processes including biological treatment, nanofiltration and ozonation coupled with disinfection. Environ Sci Water Res Technol 6:2444-2453

28. Jones RR, Stavreva DA, Weyer PJ et al (2020) Pilot study of global endocrine disrupting activity in lowa public drinking water utilities using cell-based assays. Sci Total Environ 714:136317

29. Zeng Q, Zhang S-H, Liao J, Miao D-Y, Wang X-Y, Yang P, Yun L-J, Liu A-L, Lu W-Q (2015) Evaluation of genotoxic effects caused by extracts of chlorinated drinking water using a combination of three different bioassays. J Hazard Mater 296:23-29

30. Lu W-Q, Chen D, Wu X-J, Liu A, Liu H, Wu J-J, Mersch-Sundermann V (2004) DNA damage caused by extracts of chlorinated drinking water in human derived liver cells (HepG2). Toxicology 198:351-357

31. Adams C, Wang Y, Loftin K, Meyer M (2002) Removal of antibiotics from surface and distilled water in conventional water treatment processes. J Environ Eng 128:253-260

32. Wang D, Xu Z, Zhao Y, Yan X, Shi J (2011) Change of genotoxicity for raw and finished water: role of purification processes. Chemosphere 83:14-20

33. Matilainen A, Vepsäläinen M, Sillanpää M (2010) Natural organic matter removal by coagulation during drinking water treatment: a review. Adv Colloid Interface Sci 159:189-197

34. Choi Y, Park H, Lee M, Lee G-S, Choi Y (2019) Seasonal variation of assimilable organic carbon and its impact to the biostability of drinking water. Environ Eng Res 24:501-512 
35. Picardo M, Filatova D, Nuñez O, Farré M (2019) Recent advances in the detection of natural toxins in freshwater environments. TrAC Trends Anal Chem 112:75-86

36. Brunner AM, Vughs D, Siegers W, Bertelkamp C, Hofman-Caris R, Kolkman A, ter LaakT (2019) Monitoring transformation product formation in the drinking water treatments rapid sand filtration and ozonation. Chemosphere 214:801-811

37. Shi P, Zhou S, Xiao H, Qiu J, Li A, Zhou Q, Pan Y, Hollert H (2018) Toxicological and chemical insights into representative source and drinking water in eastern China. Environ Pollut 233:35-44

38. Phungsai P, Kurisu F, Kasuga I, Furumai H (2018) Changes in dissolved organic matter composition and disinfection byproduct precursors in advanced drinking water treatment processes. Environ Sci Technol 52:3392-3401

39. Trang VN, Dan NP, Phuong LD, Thanh BX (2014) Pilot study on the removal of TOC, THMs, and HAAs in drinking water using ozone/UV-BAC. Desalin Water Treat 52:990-998

40. Chiang PC, Chang EE, Liang CH (2002) NOM characteristics and treatabilities of ozonation processes. Chemosphere 46:929-936

41. Sánchez-Polo M, Salhi E, Rivera-Utrilla J, von Gunten U (2006) Combination of ozone with activated carbon as an alternative to conventional advanced oxidation processes. Ozone Sci Eng 28:237-245

42. Park H, Kim T-Y, Woo D, Cho Y-S (2015) Comparison of O3 + GAC, O3 + $\mathrm{H} 2 \mathrm{O} 2+\mathrm{GAC}$, and GAC unit operation on natural organic matter and taste and odor causing compounds removal using a pilot plant study. Water Supply 15:1383-1395

43. Cuthbertson AA, Kimura SY, Liberatore HK, Summers RS, Knappe DRU, Stanford BD, Maness JC, Mulhern RE, Selbes M, Richardson SD (2019) Does granular activated carbon with chlorination produce safer drinking water? From disinfection byproducts and total organic halogen to calculated toxicity. Environ Sci Technol 53:5987-5999

44. Huber MM, Canonica S, Park G-Y, von Gunten U (2003) Oxidation of pharmaceuticals during ozonation and advanced oxidation processes. Environ Sci Technol 37:1016-1024

45. Westerhoff P, Yoon Y, Snyder S, Wert E (2005) Fate of endocrine-disruptor, pharmaceutical, and personal care product chemicals during simulated drinking water treatment processes. Environ Sci Technol 39:6649-6663

46. Liu J, Carr S, Rinaldi K, Chandler W (2005) Screening estrogenic oxidized by-products by combining ER binding and ultrafiltration. Environ Toxicol Pharmacol 20:269-278

47. Stackelberg PE, Gibs J, Furlong ET, Meyer MT, Zaugg SD, Lippincott RL (2007) Efficiency of conventional drinking-water-treatment processes in removal of pharmaceuticals and other organic compounds. Sci Total Environ 377:255-272

48. Cuthbertson AA, Kimura SY, Liberatore HK et al (2020) GAC to BAC: does it make chloraminated drinking water safer? Water Res 172:115432

49. Bourbigot MM, Hascoet MC, Levi Y, Erb F, Pommery N (1986) Role of ozone and granular activated carbon in the removal of mutagenic compounds. Environ Health Perspect 69:159-163

50. Schenck K, Rosenblum L, Wiese TE, Wymer L, Dugan N, Williams D, Mash H, Merriman B, Speth T (2011) Removal of estrogens and estrogenicity through drinking water treatment. J Water Health 10:43-55
51. Macova M, Toze S, Hodgers L, Mueller JF, Bartkow M, Escher BI (2011) Bioanalytical tools for the evaluation of organic micropollutants during sewage treatment, water recycling and drinking water generation. Water Res 45:4238-4247

52. Chen T, Xu Y, Liu Z, Zhu S, Shi W, Cui F (2016) Evaluation of drinking water treatment combined filter backwash water recycling technology based on comet and micronucleus assay. J Environ Sci 42:61-70

53. Maffei F, Buschini A, Rossi C, Poli P, Forti GC, Hrelia P (2005) Use of the Comet test and micronucleus assay on human white blood cells for in vitro assessment of genotoxicity induced by different drinking water disinfection protocols. Environ Mol Mutagen 46:116-125

54. Buschini A, Carboni P, Frigerio S, Furlini M, Marabini L, Monarca S, Poli P, Radice S, Rossi C (2004) Genotoxicity and cytotoxicity assessment in lake drinking water produced in a treatment plant. Mutagenesis 19:341-347

55. Monarca S, Rizzoni M, Gustavino B, Zani C, Alberti A, Feretti D, Zerbini I (2003) Genotoxicity of surface water treated with different disinfectants using in situ plant tests. Environ Mol Mutagen 41:353-359

56. Carpenter CMG, Helbling DE (2017) Removal of micropollutants in biofilters: hydrodynamic effects on biofilm assembly and functioning. Water Res 120:211-221

57. van der Linden SC, Heringa MB, Man H-Y, Sonneveld E, Puijker LM, Brouwer A, van der Burg B (2008) Detection of multiple hormonal activities in wastewater effluents and surface water, using a panel of steroid receptor CALUX bioassays. Environ Sci Technol 42:5814-5820

58. Valcárcel Y, Valdehíta A, Becerra E, López de Alda M, Gil A, Gorga M, Petrovic M, Barceló D, Navas JM (2018) Determining the presence of chemicals with suspected endocrine activity in drinking water from the Madrid region (Spain) and assessment of their estrogenic, androgenic and thyroidal activities. Chemosphere 201:388-398

59. Leusch FDL, Neale PA, Arnal C et al (2018) Analysis of endocrine activity in drinking water, surface water and treated wastewater from six countries. Water Res 139:10-18

60. Conley JM, Evans N, Cardon MC et al (2017) Occurrence and in vitro bioactivity of estrogen, androgen, and glucocorticoid compounds in a nationwide screen of United States stream waters. Environ Sci Technol 51:4781-4791

61. Medlock Kakaley EK, Blackwell BR, Cardon MC et al (2020) De facto water reuse: bioassay suite approach delivers depth and breadth in endocrine active compound detection. Sci Total Environ 699:134297

62. Medlock Kakaley E, Cardon MC, Evans N et al (2021) In vitro effects-based method and water quality screening model for use in pre- and postdistribution treated waters. Sci Total Environ 768:144750

\section{Publisher's Note}

Springer Nature remains neutral with regard to jurisdictional claims in published maps and institutional affiliations.

\section{Submit your manuscript to a SpringerOpen ${ }^{\circ}$ journal and benefit from:}

- Convenient online submission

- Rigorous peer review

- Open access: articles freely available online

- High visibility within the field

- Retaining the copyright to your article

Submit your next manuscript at springeropen.com 